Revista Española de Derecho Internacional Sección PRÁCTICA ESPAÑOLA DE DERECHO INTERNACIONAL

Vol. 70/1, enero-junio 2018, Madrid, pp. 261-284 http://dx.doi.org/10.17103/redi.70.1.2018.3.01 (C) 2018 Asociación de Profesores de Derecho Internacional y Relaciones Internacionales ISSN: 0034-9380; E-ISSN: 2387-1253

\section{PRÁCTICA ESPAÑOLA DE DERECHO INTERNACIONAL}

Esta sección podrá albergar Estudios y otros textos doctrinales de extensión más breve referidos a la práctica española en Derecho internacional y Relaciones internacionales. Los Estudios que se publiquen en esta sección habrán sido sometidos al proceso de evaluación por pares y al resto de los requisitos editoriales exigidos para todos los Estudios. Por razón de la materia abordada, en este número se incorpora el estudio del Profesor Antonio Pastor Palomar que, como tal, ha sido sometido a dicho proceso de evaluación y requisitos editoriales.

\title{
LA SOLUCIÓN DE CONTROVERSIAS DE DOBLE IMPOSICIÓN EN ESPAÑA: UNA PRÁCTICA CONVENCIONAL PECULIAR ENCAMINADA AL ARBITRAJE
}

\author{
Antonio Pastor Palomar*
}

SUMARIO: 1 . INTRODUCCIÓN.-2. DOS PILARES PARA LA MEJORA DEL SISTEMA FISCAL INTERNACIONAL.-2.1. Plan de Acción BEPS y Directiva UE contra la elusión fiscal.-2.2. Estándar Común de Información.-3. LOS ACUERDOS EN LOS PROCEDIMIENTOS AMISTOSOS DE LOS CDI DE ESPAÑA.-3.1. El objeto y los diferentes elementos de los procedimientos amistosos.-3.2. El acto unilateral previo y el acuerdo entre autoridades competentes sobre la imposición no conforme al CDI.-3.3. El acuerdo de interpretación o de aplicación del CDI.-3.4. El acuerdo para casos de doble imposición no previstos en el CDI.-4. EL ARBITRAJE EN LOS PROCEDIMIENTOS AMISTOSOS.-4.1. La naturaleza jurídica internacional del arbitraje.-4.2. Rasgos del arbitraje en los CDI de España.-4.3. El arbitraje en la Convención BEPS 2016.-4.4. El arbitraje fiscal en el marco de la UE.-5. CONCLUSIONES.

\section{INTRODUCCIÓN}

1. En los últimos años se está produciendo una reforma sustancial del sistema de cooperación fiscal internacional propiciada por la crisis financie-

* El presente trabajo se enmarca en el contrato art. 83 LOU (ref.: V573) titulado «Estudios teórico-prácticos de Derecho internacional público, entre la URJC y Herbert Smith Freehills Spain LLP». Antonio Pastor Palomar es Profesor Titular de Derecho internacional público en la Universidad Rey Juan Carlos (antonio.pastor@urjc.es) y consultor de HSF. Todas las páginas web de referencia han sido consultadas por última vez el 30 de junio de 2017. 
ra, y dirigida por la Organización para la Cooperación y el Desarrollo Económico (OCDE) junto al G20. Los dos pilares interrelacionados de la reforma son, de un lado, la acción contra la erosión de la base imponible y el traslado de beneficios a jurisdicciones de fiscalidad reducida o nula, perjudicando a los territorios donde la empresa crea valor y realiza su actividad económica sustantiva (en inglés, Base Erosion and Profit Shifting o BEPS); de otro lado, la aprobación de nuevos estándares internacionales de intercambio automático de información sobre cuentas financieras entre las jurisdicciones fiscales (en inglés, Common Reporting Standard o CRS). El objetivo general de aquella reforma internacional es el de avanzar hacia la justicia fiscal mediante el reforzamiento del sistema de lucha contra el fraude y la evasión fiscales.

2. Estados, jurisdicciones fiscales no estatales y organizaciones internacionales se han comprometido a adoptar las medidas pertinentes para cumplir con esas reformas en varios planos: en las legislaciones y prácticas internas, y en relación con la celebración o aplicación de tratados y de otros instrumentos internacionales. Al haberse comprobado que la doble imposición incita al fraude y a la evasión fiscal, España ha asumido junto a una veintena de Estados miembros de la OCDE el compromiso político de mejorar la efectividad de sus convenios bilaterales de doble imposición (CDI), cuyos textos se basan, con carácter general, en el Modelo OCDE de Convenio Tributario sobre la Renta y el Patrimonio de 22 de julio de 2010 (en adelante, Modelo de Convenio OCDE) ${ }^{1}$. Se pretende llegar a un estándar mínimo en la resolución de controversias que perfeccione los procedimientos amistosos y, también, que incluya el arbitraje preceptivo y vinculante en los nuevos CDI o en enmiendas a los vigentes ${ }^{2}$. Como es sabido, los procedimientos amistosos y arbitrales están incluidos desde 2008 en el art. 25 del citado Modelo de Convenio OCDE que, como luego se dirá, tiene un carácter de soft law.

3. Estos procedimientos dan lugar a actos unilaterales, a acuerdos de aplicación de los CDI y, en algunos casos, a un sistema arbitral internacional de solución de controversias o a modos alternativos de resolución de litigios (conciliación, mediación, pericia, adjudicación, entre otros). No son procedimientos de Derecho interno sino de Derecho internacional y de Derecho de la Unión Europea (UE). En la fase pre-arbitral del procedimiento, la tramitación (inicio, legitimación, solicitud, desarrollo de actuaciones, terminación y ejecución) se resuelve según el Derecho de cada Estado porque deben intervenir las autoridades tributarias competentes, que adoptan actos internacionales jurídicamente relevantes. Si fuera necesario llegar a un acuerdo, los instrumentos concertados de aplicación de tratados se regulan en España como acuerdos internacionales administrativos y como acuerdos internacionales

\footnotetext{
1 La última actualización es de 2014, versión en inglés disponible en http://www.oecd.org.

2 Sobre este sector del Derecho internacional fiscal, véase el trabajo de PASTOR PALOMAR, A., SoLER TAPPA, E. y EstebAN, M., «Desarrollos recientes en el procedimiento amistoso y en el arbitraje de los convenios de doble imposición de España», HSF Madrid E-Bulletin Procesal, ADR y Arbitraje, 16 de febrero de 2017, disponible en http://sites.herbertsmithfreehills.vuturevx.com/176/13418/landingpages/022017-e-briefing-arbitraje-convenio-doble-imposicion-ap-me.pdf.
} 
no normativos o políticos. Sin embargo, la DA 5. a de la Ley 25/2014, de 27 de noviembre, de tratados y otros acuerdos internacionales (LTOAI) ${ }^{3}$ ha querido excluir de su ámbito de aplicación a los «actos de aplicación de tratados internacionales para evitar la doble imposición y acuerdos sobre precios de transferencia». Como se verá en los siguientes apartados, esta exclusión del Derecho español de tratados es criticable porque no valora la auténtica naturaleza internacional de los procedimientos, porque no distingue los tipos de actos que encierran esos procedimientos, y porque no indica el régimen jurídico específico y alternativo. Así, el Derecho español tiene un serio desafío en la adaptación, a la LTOAI, al nuevo Derecho de la UE y a las pautas del nuevo sistema fiscal internacional, del Real Decreto 1794/2008, de 3 de noviembre, por el que se aprueba el Reglamento de procedimientos amistosos en materia de imposición directa (Reglamento 2008 de procedimientos amistosos). En este sentido, esta norma interna se refiere de forma muy somera e inconcreta en su art. 10 a una comisión consultiva - no denominada arbitraje- cuando dicha comisión esté prevista en un CDI. Y en relación con el Convenio 40/436/ CEE relativo a la supresión de la doble imposición en caso de corrección de los beneficios de empresas asociadas, de 23 de julio de 1990 (Convenio de Arbitraje de la UE de 1990) ${ }^{4}$, al que luego me referiré más en detalle, el Reglamento también contempla una comisión consultiva exclusivamente para los casos de doble imposición que tengan que ver con los beneficios de empresas asociadas ${ }^{5}$.

4. El presente trabajo se centra en la efectividad de los procedimientos de solución de controversias de unos CDI de España (87 en la práctica) que son tratados internacionales ${ }^{6}$, por lo que resulta inexcusable seguir un enfoque basado, principalmente, en el Derecho internacional público y en el Derecho español de tratados, sin descuidar la implicación en la materia del Derecho de la UE. Esta práctica convencional, peculiar por su compleja

3 BOE núm. 288, de 28 de noviembre de 2014.

4 DO L núm. 225, de 20 de agosto de 1990.

5 BOE núm. 278, de 18 de noviembre de 2008. Este Reglamento, modificado por última vez el 17 de noviembre de 2015 (Real Decreto 1021/2015, de 13 de noviembre, por el que se establece la obligación de identificar la residencia fiscal de las personas que ostenten la titularidad o el control de determinadas cuentas financieras y de informar acerca de las mismas en el ámbito de la asistencia mutua, BOE núm. 275, de 17 de noviembre de 2015, que transpone la Directiva 2014/107/UE del Consejo, de

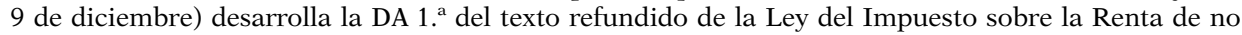
Residentes, aprobado por el Real Decreto Legislativo 5/2004, de 5 de marzo (BOE núm. 62, de 12 de marzo de 2004), según lo dispuesto en la Ley 36/2006, de 29 de noviembre, de medidas para la prevención del fraude fiscal (BOE núm. 286, de 30 de noviembre de 2006). A su vez, el Reglamento 2008 de procedimientos amistosos se ve incidido por la Ley 58/2003, de 17 de diciembre, General Tributaria, según ha sido modificada por la Ley 34/2015, de 21 de septiembre, de modificación parcial de la Ley General Tributaria, en lo que se refiere a la suspensión del procedimiento de revisión regulado en el Título V de esa Ley, cuando se simultanee con un procedimiento amistoso (BOE núm. 302, de 18 de diciembre de 2003).

6 Como reconoce claramente el Tribunal Supremo en la STS (Sala de lo Contencioso-Administrativo, Sección 2. ${ }^{\text {) }}$, de 18 de mayo de 2005, en el FD 3, al describir la naturaleza, alcance y efectos de los CDI. El TS añade que los CDI poseen una eficacia completa, es decir, «no pueden ser interpretados mediante normas internas", lo que se corresponde con el art. 96.1 de la Constitución de 1978 y con el art. 28 de la LTOAI. 
concepción internacional y por su tratamiento en el Derecho español, ha sido escasamente estudiada por los iusinternacionalistas, dejándola en manos de los fiscalistas ${ }^{7}$. Quede claro que no se profundiza en otras disciplinas relacionadas con el tema, como el Derecho fiscal, al destacarse aquí la significación de la LTOAI y del Derecho de tratados sobre los tratados y acuerdos internacionales pertinentes.

5. En el sistema internacional se está conformando una renovación de normas, de obligaciones - jurídicas y políticas-, y de estándares fiscales, surgidos a raíz de documentos programáticos de organizaciones internacionales que podrían caracterizarse dentro del Derecho blando o soft law. Así, en este tema también entra en juego ese otro plano normativo internacional. Por ejemplo, la OCDE califica como Derecho blando al Plan de Acción BEPS, y este ha tenido la capacidad de promover la adopción de instrumentos de Derecho duro (tratados como los CDI, acuerdos internacionales administrativos, directivas de la Unión Europea, y legislación tributaria nacional), y de compromisos de índole política.

6. La estructura del análisis es sencilla. En el apartado 2 se hará una presentación general del Plan de Acción BEPS y de los estándares CRS, iniciativas multilaterales que sirven para entender el contexto y alcance de lo que debe ser la aplicación práctica de los procedimientos de solución de controversias

7 Entre los iusinternacionalistas destacan los trabajos de Borrás Rodríguez, A., La doble imposición: problemas jurídico-internacionales, Madrid, Instituto de Estudios Fiscales, 1976; y «Los convenios internacionales para evitar la doble imposición internacional desde el punto de vista de la teoría general de los tratados internacionales", en VVAA, Estudios de doble imposición internacional, Madrid, Instituto de Estudios Fiscales, 1980 (pp. 22-74). También, en relación con la DA 5. a de la Ley 25/2014, de 27 de noviembre, de tratados y otros acuerdos internacionales, BOE núm. 288, de 28 de noviembre de 2014, véase el trabajo de LóPEz Escudero, M., «Disposición adicional quinta. Actos de aplicación de tratados internacionales para evitar la doble imposición y acuerdos sobre precios de transferencia», en ANDRÉS Sáenz de Santa María, P., Díez-Hochleitner, J. y Martín y Pérez de Nanclares, J. (dirs.), Comentarios a la Ley de Tratados y otros Acuerdos Internacionales, Cizur Menor, Thomson Reuters Civitas, 2015, pp. 1011-1029.

Estos mecanismos de solución de controversias internacionales han sido trabajados normalmente por los fiscalistas, como, por ejemplo, SERRANO ANTÓN, F., «El procedimiento amistoso y el arbitraje en la fiscalidad internacional», en SERRANO ANTón, F., Fiscalidad internacional (2), Madrid, Centro de Estudios Financieros, 2015, pp. 1383-1434; La resolución de conflictos en el Derecho internacional tributario: procedimiento amistoso y arbitraje, Madrid, Civitas, 2012, y «La cláusula de procedimiento amistoso de los convenios para evitar la doble imposición internacional. La experiencia española y el derecho comparado», Crónica Tributaria, vol. 114, 2005, pp. 141-174; LóPEz RiBAS, S., "Procedimientos amistosos en materia de imposición directa», Crónica Tributaria, vol. 131, 2009, pp. 35-78; PARDo CARMONA, M. y LÓPEz RiBAs, S., «Comentarios sobre la regulación reglamentaria de los procedimientos amistosos en materia de imposición directa», Impuestos, 2009, núm. 4, pp. 11-36; PAgES I Galtes, J., «La interpretación en el procedimiento amistoso de los tratados de doble imposición», en SERRANo ANTÓn, F., SIMÓN Acosta, E. y TaveIra Torres, H. (eds.), Fiscalidad y Globalización, Madrid, Aranzadi, 2012, pp. 843-879. Desde una perspectiva general de la aplicación e interpretación de los CDI, pueden destacarse las obras de García Novoa, C., "La Convención de Viena y la interpretación de los convenios de doble imposición», y de Ribes Ribes, A., "Relatoría nacional de España», en SERrano ANTón, F., Simón Acosta, E. y Taveira Torres, H. (eds.), Fiscalidad y Globalización, Madrid, Aranzadi, 2012, pp. 757-786 y pp. $373-$ 396; Hortalà i Vallvé, J., Comentarios a la red española de convenios de doble imposición, Cizur Menor, Thomson Aranzadi, 2007, pp. 767-794; RIBEs RIBEs, A., Convenios para evitar la doble imposición internacional: interpretación, procedimiento amistoso y arbitraje, Madrid, Edersa, 2003. 
de doble imposición. Los elementos compositivos de estos procedimientos constituyen el núcleo de la investigación; por ello, los elementos concertados o acuerdos amistosos serán abordados en el apartado 3, y el elemento arbitral se estudiará en el apartado 4. Se comparará su regulación en los textos de los CDI celebrados por España y se valorará su naturaleza jurídica, cuestión discutida por la doctrina, equívoca para los operadores jurídicos y fundamental para garantizar su efectividad.

\section{DOS PILARES PARA LA MEJORA DEL SISTEMA FISCAL INTERNACIONAL}

\subsection{Plan de Acción BEPS y Directiva UE contra la elusión fiscal}

7. Respecto al primer pilar de la reforma, la OCDE y el G20 iniciaron en 2013 un Plan de Acción BEPS, cuyos informes finales se presentaron en 2015 con un paquete de 15 medidas que incluyen, de mayor a menor grado de cooperación entre jurisdicciones fiscales: estándares mínimos de cumplimiento, estrategias comunes y directrices de buenas prácticas ${ }^{8}$. Los objetivos prioritarios son la mejora del funcionamiento de los mecanismos internacionales de cooperación, la adaptación a los cambios en un entorno empresarial global y digital, la lucha contra la evasión fiscal, y la prevención contra la adopción de medidas fiscales unilaterales y descoordinadas ${ }^{9}$. Ejemplo claro de descoordinación es el de la doble exención, o una imposición inferior a la ordinaria, como resultado de la aplicación de diferentes normas nacionales o de un CDI.

8. El objeto concreto de este trabajo está incluido en las acciones 14 y 15 , que se refieren a la aplicación de los mecanismos especiales de solución amistosa de conflictos de doble imposición, surgidos entre las Administraciones tributarias cuando cualquiera de ellas produce imposiciones al obligado tributario no conformes con los CDI. Sabido es que los interesados critican de estos procedimientos su complejidad procesal, su coste económico, y su frecuente ineficacia en los resultados.

9. Además, este tema es de la máxima actualidad pues los más de 3.500 CDI existentes en la sociedad internacional podrían adaptarse a estas medidas BEPS, sirviéndose de las disposiciones de una innovadora Convención

8 Véase OCDE, Proyecto BEPS. Nota explicativa: Informes finales 2015, París, Ediciones OCDE, 2016.

9 Grinberg, I. y Pauwelyn, J., «The emergence of a new international tax regime: The OECD's package on Base Erotion and Profit Shifting (BEPS)», ASIL Insights, vol. 19, 2015, núm. 24, pp. 1-5. También, SERrano ANTón, F., «El informe sobre erosión de bases imponibles y traslación de beneficios de la OCDE: origen e implementación en un marco internacional y globalizado», Derecho PUCP: Revista de la Facultad de Derecho, vol. 72, 2014, pp. 45-70; y desde una perspectiva española, véase el trabajo del mismo autor titulado, «La influencia del Plan de Acción BEPS en la tributación española: impacto en la normativa, incremento de la litigiosidad y el papel de los tribunales», Revista de Contabilidad y Tributación, CEF, vol. 391, 2015, pp. 77-110. 
multilateral para adoptar las medidas de prevención de la erosión de la base imponible y el traslado de beneficios; auténtico tratado internacional en el sentido del Derecho internacional general, que fue adoptado el 24 de noviembre de 2016 y cuya firma solemne se produjo en París el 7 de junio de 2017 (en adelante, Convención BEPS 2016) ${ }^{10}$. Como se verá más adelante, con este instrumento la solución del arbitraje fiscal internacional va ganando terreno, sobre todo, entre los Estados más prósperos de la OCDE y del G-20.

10. Al ser España un Estado miembro de la UE, debe precisarse que la intervención del Derecho de la UE en materia de fiscalidad directa e indirecta tiene como principal objetivo la armonización de los Derechos tributarios nacionales que puedan distorsionar el proceso de integración; es el caso de una doble imposición que afecte a los principios del mercado único ${ }^{11}$. Los Estados miembros poseen la competencia para la celebración y aplicación de los CDI y, por ello, España mantiene vigentes estos tratados con todos los miembros de la UE, salvo con Dinamarca que denunció el instrumento bilateral ${ }^{12}$. Obviamente, estos CDI de los Estados miembros deben respetar el Derecho de la UE ${ }^{13}$.

11. En efecto, la UE también actúa en este ámbito y ha presentado su propio plan de acción que ayude a la puesta en marcha del Plan de Acción $B E P S$, a través de la Comunicación de la Comisión Europea al Parlamento Europeo y al Consejo, de 17 de junio de 2015, relativa a un sistema de imposición de las sociedades justo y eficaz en la Unión Europea: cinco ámbitos de actuación fundamentales ${ }^{14}$. Asimismo, sobre la base del art. 115 del TFUE, la

10 El texto de la Convención e información complementaria sobre la misma pueden consultarse en el sitio web de la OCDE $h t t p: / / w w w . o e c d . o r g / t a x / t r e a t i e s / m u l t i l a t e r a l-c o n v e n t i o n-t o-i m p l e m e n t-t a x$-treatyrelated-measures-to-prevent-beps.htm.

11 Véase Hinojosa Martínez, L. M., "El derecho fiscal comunitario», en LóPez Escudero, M. y Martín y Pérez de Nanclares, J. (coords.), Madrid, McGraw Hill, 2000, pp. 251-266. También, más recientemente, Herrera Molina, P. M., «Los convenios de doble imposición ante las libertades de la UE (análisis de la jurisprudencia del TJUE)», en SERRANO ANTóN, F., op. cit., nota 7, pp. 1617-1643. En las Conclusiones del Consejo sobre la erosión de la base imponible y traslado de beneficios, de 8 de diciembre de 2015, se reconoció que «es preciso examinar los mecanismos de resolución de litigios vigentes (de doble imposición) para aumentar la seguridad jurídica de las empresas de la UE», disponibles aquí http://www.consilium.europa.eu/es/press/press-releases/2015/12/08-ecofin-conclusions-corporatetaxation/.

12 Un listado de los CDI vigentes de España puede encontrarse en los sitios web del Ministerio de Hacienda y Función Pública y de la Agencia Tributaria. La dirección del MHFP es http://www.minhafp. gob.es/es-ES/Normativa\%20y\%20doctrina/Normativa/CDI/Paginas/CDI_Alfa.aspx. La denuncia del CDI de 3 de julio de 1972 entre España y Dinamarca, BOE núm. 24, de 28 de enero de 1974, así como del Protocolo modificativo de 17 de marzo de 1999, BOE núm. 118, de 17 de mayo de 2000, produce efectos desde el 1 de enero de 2009, BOE núm. 279, de 19 de noviembre de 2008.

13 Sobre el tema, véase DE Vicente-Tutor Rodríguez, M., «Convenios de doble imposición y Derecho comunitario", Instituto de Estudios Fiscales, vol. 4, 2007, pp. 343-354. También, Magraner MoRENO, F. J., «La coordinación de los convenios para evitar la doble imposición a escala comunitaria: situación actual y perspectivas de futuro», Crónica Tributaria, vol. 137, 2010, pp. 171-197; SÁnCHEZ JiMÉNEZ, M. A., La doble imposición internacional en la Unión Europea, Madrid, La Ley, 2002.

14 COM (2015) 302 final, disponible en http://ec.europa.eu/transparency/regdoc/rep/1/2015/ES/12015-302-ES-F1-1.PDF. La COM (2015) 302 final, de 17 de junio, se completa con la Comunicación de la Comisión al Parlamento Europeo y al Consejo sobre el establecimiento de un sistema de imposición de las sociedades equitativo, competitivo y estable para la UE, COM (2016) 682 final, de 25 de octubre; 
UE ha adoptado distintas directivas con vistas a garantizar un sistema fiscal más armonizado, competitivo y equitativo, en concreto: la Directiva 2003/49/ $C E$ del Consejo, de 3 de junio, relativa a un régimen fiscal común aplicable a los pagos de intereses y cánones efectuados entre sociedades asociadas de diferentes Estados miembros ${ }^{15}$, la Directiva 2011/96/UE del Consejo, de 30 de noviembre, relativa al régimen fiscal común aplicable a las sociedades matrices y filiales de Estados miembros diferentes ${ }^{16}$, y la Directiva (UE) 2016/1164 del Consejo, de 12 de julio, por la que se establecen normas contra las prácticas de elusión fiscal que inciden directamente en el funcionamiento del mercado interior (Directiva UE contra la elusión fiscal) ${ }^{17}$. Esta última Directiva UE contra la elusión fiscal forma parte del paquete de lucha contra la elusión fiscal presentado por la Comisión el 28 de enero de $2016^{18}$. Recientemente se ha propuesto la modificación de la misma Directiva en lo que se refiere a las asimetrías híbridas con terceros países, pues su texto solo contemplaba los mecanismos híbridos asimétricos producidos por la interacción entre los regímenes del impuesto de sociedades de los Estados miembros ${ }^{19}$.

así como por las Conclusiones del Consejo sobre el mismo tema, de 6 de diciembre de 2016. En este marco, también debe mencionarse el Código de conducta sobre la fiscalidad de las empresas, adoptado por el Consejo el 1 de diciembre de 1997, que — sin ser jurídicamente vinculante- supone la asunción de compromisos políticos por los Estados miembros en el seno del Consejo en orden a derogar las medidas fiscales vigentes que constituyen competencia fiscal perniciosa, así como a abstenerse de promulgar nuevas medidas de este tipo en el futuro. El Código fue adoptado formalmente como Conclusiones del Consejo ECOFIN, de 1 de diciembre de 1997, sobre política fiscal, cuyo Anexo 1 contiene la Resolución del Consejo y de los representantes de los gobiernos de los Estados miembros reunidos en el seno del Consejo, de 1 de diciembre de 1997, relativa a un Código de Conducta sobre la fiscalidad de las empresas. Fiscalidad del Ahorro, DO C núm. 2, de 6 de enero de 1998.

15 DO L núm. 157, de 26 de junio de 2003.

16 DO L núm. 345, de 29 de diciembre de 2011, modificada por la Directiva 2013/13/UE del Consejo, de 13 de mayo (DO L núm. 141, de 28 de mayo de 2013), por la Directiva 2014/86/UE del Consejo, de 8 de julio (DO L núm. 219, de 25 de julio de 2014), y por la Directiva (UE) 2015/121 del Consejo, de 27 de enero ( $D O$ L núm. 21, de 28 de enero de 2015).

17 DO L núm. 193, de 19 de julio de 2016. Véase el comentario de Calderón Carrero, J. M. y MarTín JimÉnEZ, A., «La Directiva UE 2016/1164 contra las prácticas de elusión fiscal que inciden en el mercado interior: ¿El principio del final de un IS nacional o una pieza más de descoordinación en el nuevo orden post-BESP?», Revista de Contabilidad y Tributación, CEF, vol. 407, 2017, pp. 5-56.

18 Compuesto además por la Comunicación de la Comisión al Parlamento Europeo y al Consejo, Paquete de lucha contra la elusión fiscal: próximos pasos para lograr una imposición efectiva y una mayor transparencia fiscal en la UE, de 28 de enero de 2016, COM (2016) 23 final. También, el paquete de lucha contra la elusión fiscal incluye una Recomendación de la Comisión sobre la aplicación de las medidas contra los abusos en detrimento de los convenios fiscales, C (2016) 271 final, esto es el treaty shopping; y, en materia de transparencia e información fiscal, está la Directiva 2016/881/UE del Consejo (DO L núm. 146, de 3 de junio de 2016), que modifica la Directiva 2011/16/UE del Consejo, de 15 de febrero, relativa a la cooperación administrativa en el ámbito de la fiscalidad. Finalmente, el paquete lleva la Comunicación de la Comisión al Parlamento Europeo y al Consejo sobre estrategia exterior para una imposición efectiva, COM (2016) 24 final, que aboga por una buena gobernanza aumentando la transparencia fiscal y prestando mayor atención a los países en desarrollo.

Véase, sobre el paquete anti-elusión de la UE, CALDERón CARRERo, J. M., «La dimensión europea del Proyecto BEPS: primeros acuerdos del ECOFIN, la aprobación del mecanismo de intercambio automático de tax rulings, y el Paquete Anti-Elusión Fiscal 2016», Quincena Fiscal, vol. 76, 2016, pp. 119-154.

19 El 29 de mayo de 2017 el Consejo adoptó la Directiva sobre asimetrías híbridas con terceros países, que completa la acción BEPS aplicada por la UE. Las situaciones de asimetría híbridas se derivan de dobles deducciones, de conflictos en la calificación de los instrumentos financieros, de pagos y entidades o en la atribución de los pagos. Se trata de que el Estado miembro deniegue la deducción 
12. Y debe mencionarse la Propuesta de Directiva del Consejo relativa a los mecanismos de resolución de los litigios de doble imposición en la UE (Propuesta de Directiva sobre litigios de doble imposición), que está en fase de tramitación. Según este acto normativo, los mecanismos previstos en los CDI «no permiten resolver plenamente la doble imposición de manera oportuna en todos los casos», y el Convenio de Arbitraje de la UE, «tiene un ámbito de aplicación más limitado, ya que solo se aplica a los litigios en materia de precios de transferencia y de atribución de beneficios a los establecimientos permanentes» ${ }^{20}$. La Propuesta de Directiva establece un procedimiento amistoso, que incluye el arbitraje y otros mecanismos de solución alternativos, para los litigios de doble imposición derivados de la interpretación o aplicación de los CDI celebrados entre los Estados miembros, y surgidas del Convenio de Arbitraje de la UE.

\subsection{Estándar Común de Información}

13. El segundo pilar de la reforma del sistema fiscal internacional es el de la aprobación por el Consejo de la OCDE, el 15 de julio de 2014, del CRS o estándar para el intercambio automático de información sobre cuentas financieras $^{21}$. La cooperación administrativa en materia de intercambio de información resulta fundamental para la comprobación de la situación tributaria, así como para la efectividad de los CDI.

14. Por ello, el Modelo de Convenio OCDE contiene un artículo relativo al intercambio de información, al igual que los CDI celebrados por España, lo que resulta compatible con la asunción de otras obligaciones internacionales complementarias. De este modo, el CRS define el tipo de información financiera intercambiable, las instituciones y los contribuyentes implicados, las cuentas relevantes, así como los procedimientos de diligencia razonables que esas instituciones deben seguir ${ }^{22}$.

15. Uno de los resultados más relevantes del CRS ha sido el Acuerdo multilateral entre autoridades competentes sobre intercambio automático de información de cuentas financieras, de 20 de octubre de 2014 (Acuerdo CRS $2014)^{23}$. España lo tramitó como un acuerdo internacional administrativo,

\footnotetext{
de un pago, unos gastos o unas pérdidas, u obligue al contribuyente a incluir el pago en su renta imponible, según sea adecuado.

${ }^{20}$ COM (2016) 686 final, de 25 de octubre, considerando 3, y acuerdo del Consejo, previo al dictamen del Parlamento Europeo, de 23 de mayo de 2017 (9420/17). También, el dictamen favorable del Comité Económico y Social Europeo sobre esta Propuesta de Directiva, de 22 de febrero de 2017, reconoce la necesidad de mejora de los procedimientos amistosos de los CDI y del Convenio de Arbitraje de la UE, DO C núm. 173, de 31 de mayo de 2017.

21 OCDE, Common Reporting Standard (CRS), OECD Council, 15 de julio de 2014, disponible en http://www.oecd.org/tax/automatic-exchange/common-reporting-standard/.

22 Véase OCDE, Estándar para el intercambio automático de información sobre cuentas financieras, París, Ediciones OCDE, 2017.

${ }_{23}$ BOE núm. 193, de 13 de agosto de 2015.
} 
según consta en el acuerdo de toma de conocimiento del Consejo de Ministros de 24 de julio de 2015. Ello se debe a la doble cobertura, formal y material, que ofrecen el Convenio de Asistencia Administrativa Mutua en Materia Fiscal, de 25 de enero de 1988 (Convenio de 1988) ${ }^{24}$, y el Protocolo de enmienda de 27 de mayo de $2010^{25}$. Además, España ha presentado una declaración unilateral, de conformidad con el art. 6 del Convenio de 1988, por la que se compromete al intercambio de información desde septiembre de 2017, respecto de información referida a 2016, y siempre que otras jurisdicciones hubiesen formulado declaraciones similares; por ejemplo, contemplando la potencial conflictividad en esta materia derivada del Brexit, es el caso del Reino Unido y de Gibraltar. En efecto, otras jurisdicciones fijan esa fecha en septiembre de 2018. Con estos instrumentos se sigue el modelo FATCA con Estados Unidos, materializado en el Acuerdo entre el Reino de España y los Estados Unidos de América para la mejora del cumplimiento fiscal internacional y la implementación de la Foreign Account Tax Compliance Act (FATCA o Ley de cumplimiento tributario de cuentas extranjeras), de 14 de mayo de $2013^{26}$.

16. En el Derecho de la UE se aplica la Directiva 2011/16/UE del Consejo, de 15 de febrero, relativa a la cooperación administrativa en el ámbito de la fiscalidad ${ }^{27}$, que ha sido modificada por lo que se conoce como el CRS de la UE, esto es, la Directiva 2014/107/UE del Consejo, de 9 de diciembre ${ }^{28}$.

17. La transposición en España del Acuerdo CRS 2014 y de la Directiva 2014/107 se ha realizado mediante el Real Decreto 1021/2015, de 13 de noviembre, por el que se establece la obligación de identificar la residencia fiscal de las personas que ostenten la titularidad o el control de determinadas cuentas financieras y de informar acerca de las mismas en el ámbito de la asistencia mutua ${ }^{29}$.

24 BOE núm. 270, de 8 de noviembre de 2010.

25 BOE núm. 276, de 16 de noviembre de 2012.

26 BOE núm. 159, de 1 de julio de 2014.

27 DO L núm. 64, de 11 de marzo de 2011.

28 DO L núm. 359, de 16 de diciembre de 2014. Sobre esta Directiva 2014/107, véanse los comentarios de MARTos Belmonte, P., «El nuevo estándar global de intercambio automático de información sobre cuentas financieras de la OCDE (CRS): estructura y funcionamiento. Aplicación del mismo en la UE: Directiva 2014/107 del Consejo de 9 de diciembre de 2014», Crónica Tributaria, vol. 159, 2016, pp. 103-130. Además, ha de tenerse en cuenta la Directiva 2015/2376 del Consejo, de 8 de diciembre (DO L núm. 332, de 18 de diciembre de 2015), en lo que respecta al intercambio automático y obligatorio de información en el ámbito de la fiscalidad, y que contempla los controvertidos acuerdos tributarios previos entre Estados y empresas o contribuyentes específicos; la Directiva 2016/881 del Consejo, de 25 de mayo (DO L núm. 146, de 3 de junio de 2016); y la Directiva 2016/2258, de 6 de diciembre (DO L núm. 342, de 16 de diciembre de 2016), en lo que se refiere al acceso de las autoridades tributarias a información contra el blanqueo de capitales.

29 BOE núm. 275, de 17 de noviembre de 2015. 


\section{LOS ACUERDOS EN LOS PROCEDIMIENTOS AMISTOSOS DE LOS CDI DE ESPAÑA}

\subsection{El objeto y los diferentes elementos de los procedimientos amistosos}

18. Partiendo de que un CDI pretende eliminar la doble imposición, prevenir la evasión fiscal y distribuir las potestades tributarias en orden a gravar una renta, el objeto de los procedimientos amistosos es la resolución de una controversia de doble imposición jurídica o económica. Según la OCDE, «la doble imposición jurídica internacional puede definirse como la aplicación de impuestos sobre la renta en dos (o más) Estados sobre un mismo contribuyente y una misma renta ${ }^{30}$. Casos típicos son los de una empresa residente en España (Estado de residencia) que obtiene rentas situadas en México (Estado de la fuente), y los dos Estados someten esas rentas a imposición; o el de una persona física o una empresa respecto de la que dos Estados convenidos (el CDI de España y México, por ejemplo) entienden con base en sus respectivas legislaciones nacionales que reside o que posee un establecimiento permanente en su territorio. Y la OCDE considera que «la doble imposición económica hace referencia a la inclusión de la misma renta por la administración tributaria de más de un Estado en la base imponible de contribuyentes distintos ${ }^{31}$. Suele suceder en los casos de precios de transferencia (art. 9 del Modelo de Convenio de la OCDE); es decir, los precios a los que una empresa transmite bienes materiales y activos intangibles, o presta servicios, a empresas asociadas. Sobre estos precios convenidos entre empresas asociadas, las jurisdicciones tributarias practican ajustes de los beneficios imponibles (teniendo en cuenta la plena competencia, es decir, el valor de mercado y las operaciones entre partes independientes en relación, por ejemplo, con intereses sobre préstamos) que, si no son ajustes correlativos, dan lugar a que el grupo multinacional tribute dos veces por una misma renta.

19. La doble imposición por los precios de transferencia puede resolverse mediante el procedimiento amistoso previsto en el respectivo CDI, y prevenirse mediante los acuerdos previos sobre precios de transferencia. Estos acuerdos internacionales pueden suscribirse entre el contribuyente y la Administración fiscal, o entre la Administración fiscal del Estado de residencia de la empresa y la Administración fiscal del otro Estado. En ambos casos el fin es regular - antes de realizar la transacción objeto del ajuste- los criterios de determinación de esos precios y, de esta manera, que el contribuyente pueda adaptarse a ellos y evitar posibles casos de doble imposición ${ }^{32}$. Resulta

${ }^{30}$ OCDE, Manual para la aplicación efectiva del procedimiento amistoso, París, Ediciones OCDE, 2007, p. 10.

31 Ibid., p. 10. Véanse las Directrices de la OCDE aplicables en materia de precios de transferencia a empresas multinacionales y administraciones tributarias, París, Ediciones OCDE, 2010.

32 Véase Hernández Vázouez, O. y Justo Alonso, A., "Precios de transferencia», Cuadernos de Formación, Instituto de Estudios Fiscales, vol. 15, 2012, pp. 51-63; y sobre la naturaleza de estos acuer- 
criticable que la DA 5. ${ }^{a}$ de la LTOAI haya excluido de su aplicación tanto a los acuerdos de los procedimientos amistosos como a estos acuerdos previos sobre precios de transferencia, como si no fuesen actos concertados de aplicación de un tratado internacional. En los párrafos que siguen se sostiene que la redacción de esa DA 5. a debía haber establecido la especificidad de estos acuerdos, evitando una exclusión absoluta del Derecho de tratados, y mencionando la legislación nacional aplicable como lex specialis ${ }^{33}$.

20. Ya se ha dicho que los procedimientos amistosos tienen naturaleza jurídica internacional, y esto es así en todos sus componentes. El Derecho internacional (el CDI u otro tipo de tratado) fija los elementos básicos y el alcance del procedimiento amistoso, y cada Derecho interno regula la aplicación efectiva por las autoridades tributarias competentes ${ }^{34}$. Además de las controversias de doble imposición, los procedimientos amistosos comprenden acuerdos generales de interpretación o aplicación de los CDI, e incluso prevén consultas y acuerdos en los casos no previstos en los CDI que podrían caracterizarse como acuerdos de enmienda de estos.

21. En efecto, la mejora de la efectividad de los procedimientos de solución de conflictos de doble imposición implica que las jurisdicciones fiscales determinen su verdadera naturaleza y que, consecuentemente, distingan sus elementos compositivos, sobre la base del art. 25 del Modelo de Convenio de la OCDE, a saber:

- Primero, se prevén una serie de acuerdos amistosos entre las autoridades competentes: el acuerdo sobre la imposición no conforme al CDI (párrs. 1 y 2 del art. 25), en el marco del procedimiento amistoso sobre la imposición no conforme. El acuerdo de interpretación o de aplicación de un CDI (párr. 3 del art. 25), que surge del procedimiento amistoso interpretativo. Y el acuerdo para la eliminación de la doble imposición en un caso no previsto en el CDI (párr. 3 del art. 25), que se vincula también al procedimiento amistoso sobre la imposición no conforme.

- Segundo, se dispone el posible establecimiento de una comisión mixta como órgano de comunicación entre las autoridades competentes.

- Tercero y último, se contempla un procedimiento arbitral suplementario y complementario de la fase concertada o de los acuerdos amistosos.

22. Veamos todos estos elementos de los procedimientos amistosos regulados en los CDI de España, teniendo en cuenta tanto el Derecho internacional como el Derecho español.

\footnotetext{
dos previos, véase LóPEz Escudero, M., op. cit., nota 7, pp. 1028-1029, para quien aquellos son meras prácticas administrativas.

${ }^{33}$ Los acuerdos previos de valoración de operaciones entre personas o entidades vinculadas se regulan en el capítulo VII, arts. 21-36, del Real Decreto 634/2015, de 10 de julio, por el que se aprueba el Reglamento del Impuesto sobre Sociedades, BOE núm. 165, de 11 de julio de 2015.

${ }^{34}$ En este sentido se pronuncia SERrANo ANTÓN, F., en «El procedimiento amistoso y el arbitraje en la fiscalidad internacional», op. cit., nota 7, p. 1393, cuando afirma que «el procedimiento amistoso no es sino un procedimiento especial incluido en un convenio internacional y desarrollado habitualmente en el marco de la legislación interna de cada Estado».
} 


\subsection{El acto unilateral previo y el acuerdo entre autoridades competentes sobre la imposición no conforme al CDI}

23. En el procedimiento amistoso participan el contribuyente junto a las autoridades competentes de los dos Estados. En España, el art. 3 del Reglamento 2008 de procedimientos amistosos se refiere al derecho de los obligados tributarios a iniciar los procedimientos. Ahora bien, el arreglo amistoso es principalmente interestatal o interadministrativo, con una participación indirecta del contribuyente (entrega de información adecuada a la autoridad competente, cooperación en el procedimiento, y exposición a la autoridad competente, verbalmente o por escrito, del tipo de solución pretendida). La solución depende de las autoridades competentes de los dos Estados, preservándose su soberanía fiscal, salvo si se puede aplicar el arbitraje a instancia del contribuyente en las condiciones previstas en el tratado internacional. El contribuyente podrá también interponer recursos internos en cada Estado, tras la adopción de la medida por la Administración tributaria o una vez denegada su reclamación contra aquella ${ }^{35}$.

24. En la primera fase del procedimiento amistoso, el contribuyente presenta su caso ante la autoridad competente dentro del plazo de los tres años siguientes a la primera notificación de la medida administrativa. Esta autoridad puede resolver unilateralmente la reclamación mediante un acto de carácter singular por su objeto y por su confidencialidad, pues afecta al interés de un particular; por ejemplo, la reclamación podría versar sobre un error material acerca de la residencia fiscal del contribuyente, lo que incide en el concepto de residente previsto en el CDI. Según el Derecho internacional general, estos actos unilaterales de aplicación de un tratado son convencionales por naturaleza, ya que su valor y sus efectos dependen del tratado del que emanan. Puesto que la eficacia de la primera fase del procedimiento amistoso se encuentra en el Derecho internacional convencional, en la LTOAI debería haberse incluido una disposición que previera su especificidad, no su exclusión del Derecho español de tratados. De esta manera, se exceptuaría la aplicación del art. 24 de la LTOAI que prevé la publicación en el $B O E$ de «los actos unilaterales dependientes del tratado». Además, el Derecho tributario nacional que regule el procedimiento amistoso deberá respetar el principio de que el Derecho internacional se rige por sus propias reglas, a las que indudablemente se conforma el Derecho español de tratados. El acto unilateral resolutorio no es autónomo, pues no crea nuevas obligaciones y derechos, sino que se funda en el CDI. A estos efectos, el CDI se interpretará con las reglas del art. 31 de la Convención de Viena de 1969 sobre el Derecho de los tratados (Convención de Viena de 1969) 36; también, se fundará en el Derecho nacional si este responde al CDI.

35 La DA 21 de la Ley General Tributaria estipula que en caso de que «se simultanee un procedimiento amistoso en materia de imposición directa previsto en los convenios o tratados internacionales con un procedimiento de revisión de los regulados en el Título V de esta Ley, se suspenderá este último hasta que finalice el procedimiento amistoso».

36 Convenio de Viena sobre el Derecho de los Tratados, adoptado en Viena el 23 de mayo de 1969, $B O E$ núm. 142, de 13 de junio de 1980. 
De cualquier manera, para el Derecho internacional general ese acto unilateral convencional será obligatorio jurídicamente por su contenido y por las circunstancias de su adopción; además, con base en los principios internacionales de la buena fe y de la confianza recíproca, producirá unos efectos para el contribuyente que impedirán que la autoridad competente vuelva contra su propio acto (estoppel) arbitrariamente, por ejemplo, revocándolo ${ }^{37}$. El acto unilateral incoado - ya que al menos la autoridad competente verifica la fundamentación de la reclamación y decide que su solución no será satisfactoria- ${ }^{38}$, puede considerarse una práctica de Derecho internacional atribuible a un Estado, regulada en el art. 31.3.b) de la Convención de 1969 como medio de interpretación auténtica y ulterior del CDI, a condición de que esa práctica contribuya a la segunda fase del procedimiento, esto es, al acuerdo sobre imposición no conforme ${ }^{39}$, e incluso al acuerdo de interpretación de las partes. La solución unilateral potencial no es el acuerdo, pero debe contribuir a él. Esta concepción de la práctica ulterior de un tratado ha sido reconocida por la Comisión de Derecho Internacional ${ }^{40}$, y va en línea con el Plan de Acción $B E P S$ pues, como veremos a continuación, ofrece coherencia a la naturaleza de todos los elementos del procedimiento amistoso.

25. En efecto, en caso de que esa autoridad competente no esté en condiciones de adoptar una solución satisfactoria, por sí misma, se abre la segunda fase del procedimiento, pues esta podrá acudir a la autoridad competente del otro Estado parte para tratar de alcanzar un acuerdo amistoso de solución

37 El art. 26 de la Convención de 1969 dispone el pacta sunt servanda, esto es, que «todo tratado en vigor obliga a las partes y debe ser cumplido por ellas de buena fe». La OCDE, en el Manual para la aplicación efectiva del procedimiento amistoso, op. cit, nota 29, p. 14, expresa así el valor de esta práctica: «En la resolución de los PROCAMIS, las conversaciones entre autoridades competentes deben estar bien fundamentadas, ser justas y objetivas, analizando cada caso en función de sus propias circunstancias y no de los resultados alcanzados en la resolución de otros casos [...]. Como parte de este criterio bien fundamentado para la resolución de los PROCAMIS, las autoridades competentes deben ser coherentes en sus posiciones, aplicar el principio de reciprocidad y no variar de criterio en cada caso, dependiendo de la postura que genere mayor recaudación».

38 En este sentido, el art. 8 del Reglamento de 2008 sobre procedimientos amistosos regula la admisión motivada del inicio de las actuaciones.

39 Según el Modelo de Convenio OCDE, de la primera a la segunda fase se pasa cuando la autoridad competente entiende que la reclamación está fundada y que ella no puede «adoptar una solución satisfactoria». Esto no significa que su postura unilateral no pueda llegar a conformar un acuerdo bilateral.

40 Primer informe sobre los acuerdos ulteriores y la práctica ulterior en relación con la interpretación de los tratados, A/CN.4/660, 19 de marzo de 2013, párrs. 121-123, que dicen así: "Los tribunales internacionales han reconocido que el comportamiento de autoridades secundarias o incluso de otros agentes puede ser también (además de los funcionarios de alto nivel en el sentido del art. 7 de la Convención de Viena de 1969) un comportamiento ulterior pertinente para la interpretación de un tratado [...] cuando en el plano internacional se considere que estos son responsables de la aplicación del tratado. [...] en el laudo relativo al régimen fiscal de las pensiones abonadas a los funcionarios jubilados de la UNESCO residentes en Francia, el Tribunal de Arbitraje aceptó en principio que la práctica de la administración fiscal francesa de no recaudar impuestos sobre las pensiones de los empleados jubilados de la UNESCO era una práctica ulterior pertinente, aunque finalmente consideró que eran decisivos algunos pronunciamientos oficiales de una autoridad superior, a saber, el Gobierno de Francia». El arbitraje se refiere al asunto Question of the tax regime governing pensions paid to retired UNESCO officials residing in France, Laudo de 14 de enero de 2003, Reports of International Arbitral Awards, vol. XXV, p. 257, párr. 66 . 
del litigio. La obligación de pactar de las autoridades tributarias es de comportamiento, no de resultado. Una parte de la doctrina entiende que estos acuerdos sobre la imposición no conforme son puras actuaciones administrativas de aplicación de un $\mathrm{CDI}^{41}$. En mi opinión, los acuerdos sobre imposición no conforme son uno de los medios de interpretación del art. 31.3.a) de la Convención de Viena de 1969, y poseen una naturaleza análoga a la de los acuerdos internacionales administrativos regulados en el art. 2.b) y en el Título III de la LTOAI, pues cuentan con una cobertura material y formal en el CDI previo. El problema de caracterizarlos así radica en que la LTOAI exige una tramitación ante el Ministerio de Asuntos Exteriores y de Cooperación (art. 39) y una publicación de todos estos acuerdos internacionales administrativos (art. 41), mientras que estos acuerdos tributarios no se adecuan a esos trámites de los acuerdos internacionales administrativos, pues se maneja información confidencial y concreta relativa a un contribuyente, a la vez que se exige la aceptación o rechazo del acuerdo por el contribuyente ${ }^{42}$. La confidencialidad y la afectación particular no impiden que los acuerdos amistosos sobre imposición no conforme sean considerados como acuerdos internacionales administrativos especiales, pues el art. 40 de la LTOAI afirma que «los signatarios tendrán autonomía para decidir el procedimiento (de tramitación) que habrá de respetar lo establecido en el tratado que le dé cobertura» ${ }^{43}$. En el art. 14 del Reglamento de 2008 sobre procedimientos amistosos se precisa que el acuerdo se formaliza en un intercambio de cartas entre autoridades competentes que adquirirá firmeza con la aceptación expresa del obligado tributario. Este art. 40 de la LTOAI tendría que ser leído conjuntamente con la DA 5. ${ }^{\mathrm{a}}$ de la misma LTOAI. Y la disposición debería ser redactada, según proponemos, estableciendo la especialidad de estos acuerdos amistosos derivados de los CDI.

26. Los acuerdos amistosos de solución de la imposición no conforme que, en cualquier caso, serían acuerdos internacionales de ejecución de un tratado y que, en España, se caracterizarían como acuerdos internacionales administrativos especiales, forman parte de la estructura jurídica del tratado como elementos de interpretación y aplicación. Su valor internacional y en la legislación nacional se deriva del CDI relevante. Cabe plantearse, en conse-

41 López Escudero, M., op. cit., nota 7, p. 1022.

42 Véase el art. 14 del Reglamento de 2008 sobre procedimientos amistosos. Sin embargo, el contribuyente no participa en la negociación del acuerdo entre las autoridades competentes. Si el contribuyente rechazara el acuerdo podrá seguir otras vías de reparación que le ofrezca el Derecho interno.

43 A los efectos de la definición de los procedimientos amistosos, junto a los CDI habrá que tener en cuenta los documentos relevantes de la OCDE, como los Comentarios al Modelo de Convenio de la OCDE y las Directrices de la OCDE sobre precios de transferencia. Según el art. 31 de la Convención de 1969 y el art. 35 de la LTOAI, estos documentos no poseen valor normativo o interpretativo autónomo, pero son de gran ayuda para el intérprete de los CDI. Sobre el tema, véase Escobar HERnÁNDEZ, C., "Art. 35. Reglas de interpretación», en ANDrés SÁEnz de SANTA María, P., Díez-Hochleitner, J. y Martín y PÉrez de Nanclares, J. (dirs.), op. cit., nota 7, pp. 722-723. También, Grageda NúÑez, E., «La interpretación de los tratados para evitar la doble tributación, el modelo de la OCDE y sus comentarios», Revista de Derecho Económico Internacional, vol. 1, 2013, núm. 1, pp. 51-75; y ENGELEN, F. A., Interpretation of tax treaties under international law, Amsterdam, IBFD Publications BV, 2004. 
cuencia, si estos acuerdos constituyen un precedente internacional. Por principio, este tipo de práctica internacional unilateral o multilateral debe ser coherente - no coincidente - en sus resultados, lo que implica en este caso que se conozca por los operadores jurídicos, incluidos los jueces nacionales y las autoridades tributarias competentes, que deberán respetar su valor jurídico internacional, así como el carácter secreto de la información contenida en los acuerdos. Sin embargo, la OCDE deja claro que los acuerdos de solución no constituyen un precedente para el contribuyente ni para las administraciones tributarias ${ }^{44}$. Este es un rasgo más de las peculiaridades de esta práctica internacional. No debe sorprender este relativismo que también se produce en la práctica arbitral en materia de inversión extranjera, donde puede hablarse de una jurisprudencia arbitral con efectos suasorios y no vinculantes ${ }^{45}$.

27. Lo que sí es un precedente para la práctica posterior es el acuerdo de interpretación o de aplicación del CDI, que debe tramitarse en España como un acuerdo internacional administrativo, y que según algunos CDI puede dar lugar a una comisión consultiva de las autoridades competentes, distinta de la comisión arbitral que debe ser independiente de aquellas. Veamos, a continuación, este otro tipo de acuerdos constitutivos del procedimiento amistoso interpretativo.

\subsection{El acuerdo de interpretación o de aplicación del CDI}

28. El objeto de este acuerdo debe ser un problema general del texto del CDI que requiera clarificación o interpretación a favor de un conjunto de contribuyentes, no de un contribuyente en particular. El contribuyente no interviene en el procedimiento. Por ejemplo, sería el caso de un problema en la definición de un término del CDI. La doctrina española caracteriza estos instrumentos como acuerdos ulteriores en el sentido del art. 31.3.a) de la Convención de Viena de 1969 que, en el Derecho español pueden encajar en la figura de los acuerdos internacionales administrativos de la LTOAI ${ }^{46}$. En España esta calificación comporta la publicación oficial de los acuerdos (art. 41 de la LTOAI), lo que para la OCDE «mejoraría el procedimiento y resolvería por anticipado controversias futuras» ${ }^{47}$. Con la publicación oficial, estos acuerdos pasarían a formar parte del ordenamiento interno

44 OCDE, op. cit., nota 29, p. 35.

45 Sobre el tema, véase PASTOR PALOMAR, A., «Relativismo y consistencia en la jurisprudencia reciente del CIADI, con especial referencia a los casos contra Argentina», en FERnández LiESA, C., Tribunales internacionales y espacio iberoamericano, Madrid, Civitas, 2009, pp. 245-262.

46 López Escudero, M., op. cit., nota 7, pp. 1025-1026. Para este autor, la exclusión de estos acuerdos amistosos del régimen de la LTOAI no es adecuada «ya que contribuye a mantener la confusión sobre su naturaleza y efectos». Por tanto, este profesor considera que la mejor caracterización sería la de «tratados internacionales [...] de los que derivan obligaciones y derechos no solo para las administraciones tributarias nacionales que los concluyen, sino también para los contribuyentes» o, al menos, la de «acuerdos internacionales administrativos», lo que garantizaría su publicación oficial en España y su consecuente aplicación por los operadores jurídicos.

47 OCDE, op. cit., nota 29, p. 13. 
español (art. 41.4 de la LTOAI). Y según el art. 35.4 de la LTOAI sus disposiciones «se interpretarán de conformidad con el tratado que desarrollan». Además, en tanto que acuerdos internacionales de ejecución de un tratado, su relación aplicativa con el Derecho interno debe ser la misma que tenga el tratado de cobertura, es decir, rigen por analogía los arts. 28 (eficacia), 29 (observancia), 30 (ejecución) y 31 (prevalencia), teniendo que realizar el operador jurídico nacional un control de la convencionalidad del acuerdo administrativo respecto de dicho tratado. En caso de que dicho operador encuentre una disparidad formal y/o material entre los dos instrumentos, la solución más lógica sería la del art. 35.4 de la LTOAI, esto es, que el órgano nacional aplique el tratado o que interprete el acuerdo de conformidad con el tratado porque, además, el acuerdo puede contener una disposición que así lo exija ${ }^{48}$.

29. La práctica de España sobre la caracterización y tramitación de estos acuerdos ha sido errática y dispar. Unos se han publicado en el $B O E$ acertadamente y anticipando la regulación del art. 41 de la LTOAI ${ }^{49}$, otros aparecen como órdenes ministeriales ${ }^{50}$, mientras que otros solo constan en el sitio web del Ministerio de Hacienda ${ }^{51}$. El nuevo régimen de la LTOAI permite la mejora de esta práctica con la posible adopción de soluciones uniformes y coherentes, como pretende la OCDE.

30. Por mi parte, coincido en esa caracterización como acuerdos internacionales administrativos de la LTOAI ${ }^{52}$ y, una vez más, se reitera que ello debía haberse reflejado en la DA 5. ${ }^{a}$ Habría que añadir que esa será la naturaleza siempre que los acuerdos amistosos de interpretación no contengan en su texto una enmienda al CDI, como sucede con el siguiente tipo de acuerdo para casos de doble imposición no previstos en el CDI.

48 Véase, sobre este tipo de problemas aplicativos, el trabajo de PASTOR Palomar, A., «La Ley 25/2014 de tratados y otros acuerdos internacionales: examen para jueces y abogados», en PASTOR Palomar, A. (dir.), Temas relevantes de Derecho internacional público ante la jurisdicción contenciosoadministrativa, Madrid, Ministerio de Justicia, 2016, esp. pp. 16-29, p. 23. El autor comenta que esta es la solución adoptada por el Tribunal Supremo en las Sentencias de 20, 22 y 29 de junio de 2011, con ocasión de la vinculación del Acuerdo complementario de 28 de febrero de 2000 entre España y la OTAN (BOE núm. 117, de 16 de mayo de 2000; y BOE núm. 183, de 1 de agosto de 2001) con el Canje de Cartas de 13 y 18 de abril de 2000 entre el Comandante Supremo Aliado en Europa de la OTAN y el JEMAD español.

49 Acuerdo amistoso, de 30 de enero y 15 de febrero de 2006, relativo a la aplicación del CDI entre España y Estados Unidos de 22 de febrero de 1990, BOE núm. 195, de 13 de agosto de 2009, en el que se define, por ejemplo, la expresión «y cualquier otra agrupación de personas conforme al art. 3.1.d)».

50 El acuerdo entre las autoridades española y sueca sobre la aplicación del CDI bilateral de 16 de junio de 1976, se formaliza mediante la Orden del Ministerio de Hacienda, de 18 de febrero de 1980, aunque aparece entre las disposiciones generales del BOE núm. 53, de 1 de marzo de 1980.

51 Acuerdo mutuo entre las autoridades competentes de España y los Países Bajos, de 1 de enero de 2013, relativo a la aplicación del CDI de 16 de junio de 1971. El Acuerdo mutuo pretende la aplicación del CDI a los fondos mutuos cerrados en tanto que instrumento de inversión.

52 Esta calificación parece ser la otorgada por España, habiendo ya entrado en vigor la LTOAI, al Intercambio de Cartas interpretativas, de 11 y 23 de junio de 2015, del CDI España Marruecos de 10 de julio de 1978, publicado en el BOE núm. 170, de 15 de julio de 2016. 


\subsection{El acuerdo para casos de doble imposición no previstos en el CDI}

31. Este acuerdo suplementario entre autoridades competentes, no de mera ejecución de un tratado dentro de su cobertura material y formal, solo puede formalizarse y caracterizarse en España como un acuerdo de enmienda en forma simplificada, sobre la base del art. 39 de la Convención de Viena de 1969 y del art. 36.2 de la LTOAI ${ }^{53}$. En este sentido, en los Comentarios al apartado 3 del art. 25 del Modelo de Convenio OCDE se admite que el Derecho nacional de algunos Estados contratantes puedan imponer restricciones a estos acuerdos suplementarios entre las autoridades competentes y que, en estas situaciones, se requiera un "protocolo» particular ${ }^{54}$. No se puede justificar la exclusión de estos acuerdos del art. 36.2 de la LTOAI dedicada a la enmienda de los tratados y, en consecuencia, su régimen específico podría haberse precisado en la DA 5. ${ }^{a}$ Estos acuerdos de enmienda «no requieren la conclusión de un nuevo tratado internacional», sino de un acuerdo en forma simplificada según la letra $a$ ) del art. 36.2 de la LTOAI y conforme al procedimiento previsto en el apartado 3 del art. 25 del Modelo de Convenio de la OCDE. En la práctica internacional, estos procedimientos simplificados son frecuentes en los tratados multilaterales que contienen unos órganos de gestión del tratado con esas facultades de enmienda. Por consiguiente, la enmienda puede adoptarse automáticamente por las autoridades competentes ${ }^{55} \mathrm{y}$, posteriormente, a propuesta del ministro de Asuntos Exteriores y de Cooperación, el Consejo de Ministros debe tomar conocimiento de su celebración por esas autoridades competentes, así como de su entrada en vigor ${ }^{56}$. Además, les resultan aplicables las disposiciones sobre la publicación oficial (art. 24 de la LTOAI), la eficacia (art. 28 de la LTOAI), la observancia (art. 29 de la LTOAI), la ejecución (art. 30 de la LTOAI) y la prevalencia (art. 31 de la LTOAI).

32. Por el lado de la interpretación del CDI, estos instrumentos serían acuerdos ulteriores en el sentido del art. 31.3.a) de la Convención de Viena de 1969. Y es preciso distinguir estos acuerdos amistosos para casos de doble imposición no previstos en el CDI de los protocolos de enmienda a los CDI que se celebran como tratados internacionales en el sentido del art. 36.1 de la LTOAI; por ejemplo, es el caso del Protocolo al CDI entre España y el

53 Véase, sobre el concepto de enmienda en la LTOAI y su regulación general, el trabajo de GoNZÁlez Vega, J. A., "Comentario al art. 36. Enmienda», en Andrés Sáenz de Santa María, P., Díez-HoChleitner, J. y Martín y Pérez de NANClares, J. (dirs.), op. cit., nota 7, pp. 747-762.

54 OCDE, Modelo de Convenio Tributario sobre la Renta y sobre el Patrimonio. Comentarios al art. 25 sobre los acuerdos amistosos, Comité de Asuntos Fiscales de la OCDE, p. 370, disponible en http://www. gerens.cl/gerens/ModeloConvenioTributario.pdf.

55 Por tanto, no es el supuesto del art. 36.2.b) de la LTOAI, en la que el Estado interviene para aceptar o rechazar la enmienda.

56 Ha de entenderse, además, que las Cámaras parlamentarias habrían intervenido indirectamente en este procedimiento mediante la autorización del CDI que contiene semejante procedimiento de enmienda. 
Reino Unido, de 14 de marzo de 2013, celebrados en unidad de acto, y en vigor desde el 12 de junio de $2014^{57}$. Este Protocolo tiene por objeto precisar el contenido de ciertas expresiones del CDI, como plan de pensiones, fideicomiso, instrumento de inversión, y rentas inmobiliarias. Por consiguiente, se aproximan en lo material a los acuerdos amistosos de interpretación o de aplicación de un CDI, pero se diferencian de ellos en lo procedimental en que se concluyen por los órganos del Estado competentes para la celebración de un tratado, y no por las autoridades tributarias que participan en el procedimiento amistoso.

\section{EL ARBITRAJE EN LOS PROCEDIMIENTOS AMISTOSOS}

\subsection{La naturaleza jurídica internacional del arbitraje}

33. La tercera fase del procedimiento amistoso es la del arbitraje por una comisión consultiva, siempre que se haya acordado su existencia en alguno de los instrumentos internacionales que, a continuación, se exponen. El procedimiento de solución principal es el de los acuerdos amistosos, y el complementario y supletorio el del arbitraje (u otro medio alternativo de solución), con lo que ambos pueden estimular su respectiva efectividad.

34. Por lo que respecta a la normativa española, resulta evidente que esta debe ajustarse a los importantes cambios que se están produciendo en la sociedad internacional, al hilo del Plan de Acción BEPS de la OCDE y del G20, en el sentido de concretar la aplicación en España de este tipo de arbitraje. El Reglamento 2008 de procedimientos amistosos tan solo contempla en su Título III el Convenio de Arbitraje de la UE, y en el art. 10 del Título II se refiere a una comisión consultiva que esté prevista en un convenio, cuya constitución podrá solicitar el obligado tributario, y que actuará supletoriamente cuando no se haya alcanzado un acuerdo sobre determinadas cuestiones en las fases anteriores del procedimiento amistoso. El régimen de composición y actuación de la comisión consultiva dependerá de lo dispuesto en el respectivo CDI y en otros pactos bilaterales complementarios, según precisa el apartado 2 del art. 10 del mismo Reglamento. Esa norma española caracteriza siempre al arbitraje de doble imposición como de Derecho internacional convencional. Por otro lado, recuérdese que el art. 1.1 de la Ley 60/2003, de 23 de diciembre, de Arbitraje ${ }^{58}$, se aplica «a los arbitrajes cuyo lugar se halle dentro del territorio español, sean de carácter interno o internacional, sin perjuicio de lo establecido en tratados de los que España sea parte o en leyes que contengan disposiciones especiales sobre arbitraje», y que el art. 3 afirma que «esta Ley será de aplicación supletoria a los arbitrajes previstos en otras leyes». En consecuencia, en España se regulan distintos tipos de arbitraje internacional, y el arbitraje de doble imposición posee en su configura-

\footnotetext{
57 BOE núm. 118, de 15 de mayo de 2014.

58 BOE núm. 309, de 26 de diciembre de 2003.
} 
ción actual un carácter tanto internacional —incluido el Derecho de la UE-, como sui generis. Los desarrollos internacionales invitan a que se regule más concreta y claramente en el Derecho español.

35. Abundando en la internacionalidad de esta fase del procedimiento amistoso, la naturaleza y alcance de los pactos bilaterales relativos al funcionamiento de la comisión consultiva resultan equívocos, según se regulan en esa disposición del Reglamento. Estos pactos bilaterales basados en un CDI serán también acuerdos internacionales administrativos de la LTOAI. En cuanto a la ejecución de la decisión arbitral, el apartado 3 del art. 10 del Reglamento contempla que las autoridades competentes alcancen un «acuerdo» a la vista de la decisión de la comisión consultiva. La ejecución arbitral es concertada y administrativa, o sea, no requiere de ninguna vía judicial. Por razón de la materia del instrumento y del paralelismo de soluciones, el acuerdo de ejecución de la decisión arbitral también será un acuerdo internacional administrativo especial, derivado del tratado internacional de cobertura.

36. La introducción del arbitraje fiscal en el sistema español puede realizarse de tres maneras: una, mediante la modificación de los CDI vigentes con nuevos tratados bilaterales; otra, en principio más ágil, a través de la celebración de un tratado multilateral posterior, que suponga también la modificación de los bilaterales anteriores, como sucede con la Convención BEPS 2016; y la tercera, en el marco de la UE, con la adopción de un acto normativo como la Propuesta de Directiva sobre litigios de doble imposición de 2017. Véanse, a continuación, los rasgos comunes y distintivos de estos procedimientos arbitrales comenzando por el Modelo de Convenio de la OCDE, pues contiene el procedimiento que guía a los CDI y a otros instrumentos internacionales. Se señalarán tan solo los aspectos más significativos.

\subsection{Rasgos del arbitraje en los CDI de España}

37. Según el art. 25.5 del Modelo de Convenio de la OCDE el arbitraje se activa a instancia del contribuyente, cuando las autoridades competentes no hayan alcanzado un acuerdo en el plazo de dos años desde la presentación de la solicitud de resolución de la doble imposición. No puede someterse a arbitraje lo ya resuelto en fases anteriores, pues no es un recurso adicional sino suplementario. De la lectura del citado art. 25.5, de la práctica interestatal y del enfoque seguido en este trabajo, se desprenden los siguientes rasgos del arbitraje. Las autoridades competentes no autorizan el arbitraje, pero acordarán sus extremos, y este tipo de acuerdos también podrán tener la consideración de acuerdos internacionales administrativos especiales. Así, se acordarán los términos de referencia sobre la materia objeto de resolución arbitral. La comisión arbitral estará compuesta de dos árbitros, elegidos por cada autoridad tributaria, que elegirán al tercer árbitro. Los árbitros determinarán el procedimiento, incluido el alcance de la participación del contribuyente (oral y/o escrita). Los Estados contratantes financiarán a partes iguales 
el arbitraje. El laudo será escrito, motivado en el CDI, según las reglas de interpretación del Derecho internacional general, y vinculante para los Estados, salvo si el contribuyente rechaza el acuerdo de las autoridades competentes con el que se ejecute. El laudo podrá publicarse, aunque no constituirá un precedente para otras decisiones. Las autoridades competentes ejecutarán el laudo en un plazo de seis meses desde su comunicación, y será firme a menos que los tribunales de alguno de los Estados contratantes lo considere inaplicable por haberse ya resuelto el problema por un tribunal nacional. Las autoridades competentes pueden alcanzar un acuerdo antes de la emisión del laudo, considerándose resuelto el procedimiento amistoso ${ }^{59}$.

38. En los últimos años, este tipo de arbitraje solo se ha incorporado en cuatro CDI firmados por España, dentro de una tupida red de 87 tratados. Esta pobre suma puede multiplicarse con el consentimiento de la Convención BEPS 2016.

39. Tan solo dos tratados vigentes contienen disposiciones sobre el arbitraje. Primero, el Protocolo de 27 de julio de 2011, de modificación del CDI con Suiza, en vigor desde el 24 de agosto de $2013^{60}$. El Protocolo con Suiza amplía el plazo del posible acuerdo entre las autoridades competentes, anterior al arbitraje, hasta los tres años desde la presentación del caso (art. 25.5). Y se precisa que el sometimiento a arbitraje no podrá realizarse cuando una persona a la que concierna directamente el caso pueda ejercer aún el derecho de recurso en virtud de la legislación interna de cualquiera de los Estados, ante los tribunales u organismos administrativos de ese Estado para que se pronuncien sobre esas cuestiones, o cuando un tribunal $u$ organismo administrativo ya se haya pronunciado previamente sobre las mismas. También, están vigentes desde el 12 de junio de 2014 el nuevo CDI y su Protocolo con el Reino Unido, de 14 de marzo de $2013^{61}$. En este caso, el plazo del acuerdo entre las autoridades competentes será de dos años y se añade, respecto al tratado con Suiza, un supuesto de exclusión del arbitraje, cuando el caso se haya planteado en virtud del Convenio de Arbitraje de la UE. El Brexit puede modificar este punto, y los presumibles incentivos fiscales británicos tras la retirada podrían incrementar las controversias de doble imposición. Como se verá más tarde, se aplica el sistema arbitral de la Convención BEPS 2016, en sustitución del regulado en el CDI.

40. El Protocolo de 17 de diciembre de 2015 de modificación del CDI con México, de 24 de julio de $1992^{62}$, ha entrado en vigor el 27 de septiembre de $2017^{63}$. Dicho Protocolo introduce una disposición llamativa por la que

59 Un comentario sobre esta fase puede encontrarse en el trabajo de LóPEZ RIBAS, S., op. cit., nota 7. También, RiBes RiBES, A., «Técnicas arbitrales en los convenios de doble imposición: el borrador de la International Fiscal Association de 27 de septiembre de 2002», Crónica Tributaria, vol. 109, 2003, pp. $137-150$.

${ }^{60}$ BOE núm. 139, de 11 de junio de 2013.

${ }^{61}$ BOE núm. 118, de 15 de mayo de 2014.

62 BOE núm. 257, de 27 de octubre de 1994.

63 BOCG Senado, núm. 112, de 16 de junio de 2017. 
las partes acuerdan el uso del arbitraje, según las características del art. 25 del Modelo de Convenio OCDE, supeditado a que México - unilateralmente- celebre y entre en vigor un tratado para evitar la doble imposición con un tercer Estado que contenga este sistema arbitral. Pues bien, tanto México como España han firmado el 7 de junio de 2017 la Convención BEPS 2016, y los dos Estados han notificado que este CDI está cubierto por aquella ${ }^{64}$. Sin embargo, México no ha querido notificar, por el momento, que se le aplica el sistema de arbitraje del tratado multilateral.

41. El Protocolo de 14 de enero de 2013 de modificación del CDI con Estados Unidos, de 22 de febrero de $1990^{65}$, todavía no está vigente. Sin embargo, el Protocolo modifica el art. 26 del CDI mediante la inserción de una disposición sobre el arbitraje que presenta novedades respecto de la del Modelo de Convenio CDI, pues añade un apartado con normas sobre la persona interesada [que no solo es la que presente el caso a la autoridad competente sino «cualquier otra, si las hubiera, cuya obligación tributaria respecto de cualquiera de los Estados contratantes pueda verse directamente afectada por el acuerdo amistoso que pueda alcanzarse tras la consideración del caso", art. 26.6.a)], sobre el procedimiento arbitral y el intercambio de información vinculada al arbitraje. Estados Unidos no ha firmado la Convención BEPS 2016 por lo que, salvo si cambia la situación, entre España y Estados Unidos se aplicaría el sistema arbitral del CDI cuando entre en vigor.

\subsection{El arbitraje en la Convención BEPS 2016}

42. Este tratado internacional permite modificar de manera sincronizada los CDI de España y de otros Estados contratantes, respecto de los que se haya notificado al depositario su inclusión, sin necesidad de renegociarlos bilateralmente cada uno de ellos [art. 2.1.a)ii) ${ }^{66}$. La Parte V se titula significativamente: mejora de los mecanismos de resolución de controversias; y contiene unas normas sobre el procedimiento amistoso similares a las del Modelo de Convenio OCDE, pero se permite que toda parte pueda reservarse el derecho a no aplicar los términos del art. 16 de la Convención BEPS 2016 alegando que su intención es cumplir el estándar mínimo del Paquete BEPS. España ha formulado esta reserva cuyo significado no es fácil de interpretar, dada la indeterminación conceptual del estándar mínimo. Y respecto al arbitraje, regulado en la Parte VI, el art. 18 dispone que «toda parte podrá optar por aplicar esta parte (VI) respecto de sus convenios fiscales comprendidos y notificará su decisión al depositario. Esta parte (VI) será aplicable a dos

${ }^{64}$ La notificación de los CDI cubiertos por la Convención BEPS 2016 se formaliza en virtud de su art. 2.1.a)ii). El estado de firmas y declaraciones unilaterales (notificaciones, reservas) puede encontrarse en el sitio web de la OCDE http://www.oecd.org/tax/treaties/beps-mli-signatories-and-parties.pdf.

65 BOE núm. 306, de 22 de diciembre de 1990.

66 Los arts. 31 y 32 de la Convención BEPS 2016 prevén la constitución de una Conferencia de las Partes como órgano de solución de las dudas sobre su interpretación o aplicación. 
jurisdicciones contratantes respecto de un convenio fiscal comprendido, únicamente cuando ambas jurisdicciones contratantes hayan remitido la notificación correspondiente». En efecto, España ha notificado que le es aplicable la Parte VI sobre arbitraje, y que la Convención BEPS 2016 cubre a sus CDI que ya disponen el arbitraje, tanto a los vigentes con el Reino Unido ${ }^{67}$, Sui$\mathrm{za}^{68}$ y México ${ }^{69}$, como a los no vigentes con Estados Unidos. El art. 26 afirma que la Parte VI se aplicará en sustitución o en ausencia de disposiciones arbitrales en un CDI cubierto. También, España ha incluido en su ámbito a los CDI con los Estados miembros de la UE, lo que se ha de poner en relación con la Propuesta de Directiva sobre litigios de doble imposición de 2017. De conformidad con el art. 28.2.a), España ha formulado una reserva en relación con los casos que pueden optar al arbitraje (casos sobre las normas antiabuso de los CDI cubiertos, casos que implican algún tipo de sanción fiscal, algunos casos sobre precios de transferencia, los casos sometidos al arbitraje del Convenio de Arbitraje de la UE según pueda enmendarse, y casos que las autoridades competentes no entienden susceptibles de arbitraje). Esta reserva está sujeta a aceptación por otras partes según el art. 28.2.b). El art. 36 prevé unas fechas y criterios para que surta efectos el arbitraje en relación con determinados casos.

43. Explicado en términos muy básicos, el arbitraje de la Convención BEPS 2016 se caracteriza por ser obligatorio y vinculante (art. 19), se activa a instancia del contribuyente, y se prevé para los casos no resueltos por las autoridades competentes. La decisión arbitral requerirá del acuerdo amistoso de las autoridades competentes. También, se regula la designación de los árbitros (art. 20), la confidencialidad del procedimiento arbitral (art. 21), y unas normas procedimentales subsidiarias del acuerdo de las autoridades competentes (art. 23). Estos rasgos principales coinciden con los elementos típicos de la práctica arbitral internacional con participación de particulares, a saber: un sistema consentido por los Estados interesados previamente al surgimiento de una controversia, la buena fe en un procedimiento flexible, la decisión de un tercero imparcial creado ad hoc y temporalmente, la aplicación del Derecho internacional (el CDI en cuestión) y, finalmente, la decisión definitiva y obligatoria aunque ejecutada, en estos casos, mediante el acuerdo amistoso de las autoridades competentes.

44. La compleja aplicación de la Convención BEPS 2016 pone de manifiesto la importancia de que el operador jurídico utilice adecuadamente el Derecho de tratados.

${ }^{67}$ Reino Unido ha notificado al depositario que la Convención BEPS 2016 se aplica al CDI con España y, además, que se le aplica el sistema arbitral de la Parte VI.

68 Suiza no ha incluido el CDI de España entre los cubiertos por la Convención BEPS 2016, aunque sí ha notificado que se le apliquen las disposiciones sobre arbitraje. Por consecuencia, se aplica el arbitraje previsto en el CDI.

69 A México no se le aplica la Parte VI sobre el sistema arbitral. 


\subsection{El arbitraje fiscal en el marco de la UE}

45. España y el resto de Estados miembros se rigen por el Convenio de Arbitraje de la UE, que introduce ese modo de solución exclusivamente para la eliminación de la doble imposición en caso de rectificación de beneficios entre empresas asociadas. A diferencia del Modelo de Convenio OCDE, el arbitraje no se inicia a instancia del contribuyente sino cuando las autoridades competentes no lleguen a un acuerdo en el plazo de dos años, en cuyo caso deberán constituir una comisión consultiva, como refleja el art. 29 del Reglamento 2008 sobre procedimientos amistosos. Puede suceder el solapamiento del Convenio de 1990 con un CDI, si la situación se produce entre Estados miembros de la UE, a lo que el contribuyente debe dar respuesta decidiendo qué cuestión somete al procedimiento de uno u otro tratado. En consecuencia, si se elige un CDI, también se podrá aplicar el arbitraje de la Convención BEPS 2016.

46. La Propuesta de Directiva sobre litigios de doble imposición de $2017^{70}$ amplía el ámbito material del Convenio de Arbitraje de la UE. Se aplica a litigios entre Estados miembros por la aplicación e interpretación de sus CDI (art. 1). La persona afectada es cualquier residente en un Estado miembro directamente afectada por la imposición [art. 2.1.d)]. Dentro del procedimiento amistoso, se prevé la creación de una comisión consultiva compuesta por entre tres y cinco árbitros independientes que podrá emitir un dictamen vinculante a menos que se acuerde una solución alternativa (art. 9). La decisión final será vinculante para los Estados miembros, no constituirá un precedente y deberá aceptarse por la persona afectada (art. 14.4).

\section{CONCLUSIONES}

47. La solución de conflictos de fiscalidad internacional ha entrado en una nueva era de la mano de la OCDE y del G-20, con el objetivo último de la mejora de la efectividad de los procedimientos de solución de controversias de doble imposición. La UE se ha sumado a estas reformas y ha adoptado recientemente medidas muy relevantes para resolver los litigios entre los Estados miembros. En la OCDE destaca la firma de la Convención BEPS 2016 y, en la UE, la adopción de la Propuesta de Directiva sobre litigios de doble imposición de 2017.

48. Una de las principales líneas de mejora es la del impulso al arbitraje fiscal, así como a otros medios alternativos de solución, que actúan en la última fase del conocido como procedimiento amistoso.

49. El papel de los Derechos nacionales y de los operadores jurídicos en la materia es muy importante para concretar la efectividad del procedimiento. Sin embargo, el Derecho español no ofrece respuestas claras acerca de

\footnotetext{
70 La Directiva deberá transponerse antes del 30 de junio de 2019 (art. 21).
} 
la naturaleza de los acuerdos que componen el procedimiento pre-arbitral y post-arbitral, o en relación con la regulación y el alcance del arbitraje fiscal. Además, la LTOAI contiene una DA 5. ${ }^{a}$ de redacción desafortunada. Ese panorama legislativo nacional debe perfeccionarse, y en este trabajo se realizan algunas aportaciones interpretativas y aplicativas sobre la base del Derecho internacional público.

50. Un mejor conocimiento de estos procedimientos y de sus novedades por parte del contribuyente y de los operadores jurídicos puede ser útil para la planificación fiscal empresarial y su control estatal, o sea, para la prevención y la solución de conflictos tributarios con repercusión en las relaciones económicas internacionales.

\section{RESUMEN}

\section{LA SOLUCIÓN DE CONTROVERSIAS DE DOBLE IMPOSICIÓN EN ESPAÑA: UNA PRÁCTICA CONVENCIONAL PECULIAR ENCAMINADA AL ARBITRAJE}

El Paquete BEPS de la OCDE y del G20 hace frente a la planificación fiscal que explotan las lagunas de las normas fiscales nacionales e internacionales. El BEPS ofrece herramientas a los gobiernos para mejorar el funcionamiento de los procedimientos de solución de las controversias fiscales internacionales, como los procedimientos amistosos y el arbitraje. El presente trabajo aborda la práctica española en la materia y subraya la necesidad de aplicar efectivamente la legislación nacional, así como los nuevos tratados. Cuestión clave es la consideración de la Ley de tratados y otros acuerdos internacionales en la aplicación de estos procedimientos. Además, se analizan los distintos tipos de arbitraje de doble imposición que España debe aplicar a partir de la vigencia de estas reformas normativas nacionales e internacionales.

Palabras clave: acuerdo amistoso, arbitraje, Unión Europea, Tratados, Acuerdos internacionales administrativos.

\section{ABSTRACT \\ DOUBLE TAXATION DISPUTE SETTLEMENT IN SPAIN: A PECULIAR CONVENTIONAL PRACTICE AIMING AT ARBITRATION}

The OECD-G20 Base Erosion and Profit Shifting (BEPS) Package refers to tax planning strategies that exploit gaps and mismatches in national and international tax rules. BEPS provides tools to governments so as to improve the functioning of international tax dispute settlement procedures, such as the mutual agreement procedures and arbitration. This paper deals with Spain's international practice on this subject matter and underlines the need to apply the national legislation as well as the new treaties effectively. A key part of it is the Law on treaties and other international agreements which should be taken into consideration to implement the procedures. Moreover, there is an analysis of the different double taxation arbitration systems that Spain is bound to follow from the entry into force of the national and international legislative reforms.

Keywords: mutual agreement, arbitration, European Union, Treaties, International Administrative Agreements. 